\title{
Assessing the nonhuman primate reservoir of Schistosoma mansoni in Africa: a systematic review
}

\author{
Lindsay Richards ${ }^{1}$, Berhanu Erko ${ }^{2}$, Keerati Ponpetch ${ }^{3,5}$, Sadie J. Ryan ${ }^{4,5}$ and Song Liang ${ }^{3,5^{*}}$ (D)
}

\begin{abstract}
Background: Reports of natural infections of Schistosoma mansoni in a number of species of nonhuman primates (NHPs) in Africa, coupled with the substantial overlap of NHP habitats and human schistosomiasis endemic areas, has led to concerns about the role of NHPs in the transmission of human schistosomiasis. We conducted a systematic review of the literature to describe the current scope of knowledge for Africa, for the NHP species implicated, their geographical distribution, infection rates with S. mansoni, and to discuss the implications for public health and conservation.
\end{abstract}

Main text: A systematic search of the literature was performed using PubMed, Web of Science, Google Scholar, the World Health Organization (WHO) library database, World Cat, and ScienceDirect without any language restriction. Studies examining S. mansoni infection of any African NHP species were included. Study types, primate species, their geographical distribution, and parasite diagnostic techniques reported in the studies were qualitatively summarized. Data for species with sample sizes $\geq 10$ were included in the meta-analysis. We assessed the reported infection rate, and used a random-effects model to estimate the summary infection rates and $95 \%$ confidence intervals $(\mathrm{Cls})$. We assessed heterogeneity among studies using the $P^{2}$ statistics. Twenty-nine publications, from 1960 to 2018, were identified and included in the review. The studies examined a total of 2962 primates belonging to 22 species in 11 genera across ten countries (Cameroon, Eritrea, Ethiopia, Gabon, Kenya, Nigeria, Senegal, Tanzania, Uganda, and Zimbabwe), and S. mansoni infections were found in nine species of five genera in all countries. When we excluded studies with sample sizes $<10$, data from 24 studies on 11 species of primates in three genera in ten countries remained in the meta-analysis. The overall pooled estimate of infection rate was 10\% (95\% Cl: 6-16\%) with high heterogeneity $\left(P^{2}=94.77 \%\right)$ across countries and species/genera. Among the three genera, Pan had the highest infection rate of 15\% (95\% Cl: 0-55\%), followed by Papio at 11\% (95\% Cl: 6-18\%), and Cercopithecus at 5\% (95\% Cl: 0-14\%). The association between NHP and human infections was positive, but not significant, due to low study sample matches and high variation.

Conclusions: Our findings suggest that S. mansoni infection rate is high in African NHPs, with substantial heterogeneities across species/genera and countries in Africa. Given the evidence for potential spillover and spillback of S. mansoni between African NHPs and humans, further research is urgently needed to understand ecology and mechanisms of transmission of the parasite between NHP and human hosts, in order to inform control strategies of this important neglected tropical disease.

Keywords: Schistosoma mansoni, Nonhuman primate, Infection, Transmission, Systematic review, Africa

\footnotetext{
*Correspondence: songliang@ufl.edu

${ }^{3}$ Department of Environmental and Global Health, College of Public Health

and Health Professions, University of Florida, Gainesville, FL 32610, USA

${ }^{5}$ Emerging Pathogens Institute, University of Florida, Gainesville, FL 32610,

USA

Full list of author information is available at the end of the article
}

C The Author(s). 2019 Open Access This article is distributed under the terms of the Creative Commons Attribution 4.0 International License (http://creativecommons.org/licenses/by/4.0/), which permits unrestricted use, distribution, and reproduction in any medium, provided you give appropriate credit to the original author(s) and the source, provide a link to the Creative Commons license, and indicate if changes were made. The Creative Commons Public Domain Dedication waiver (http://creativecommons.org/publicdomain/zero/1.0/) applies to the data made available in this article, unless otherwise stated. 


\section{Multilingual abstracts}

Please see Additional file 1 for translations of the abstract into the five official working languages of the United Nations.

\section{Background}

Schistosomiasis is one of the most important neglected tropical diseases (NTDs) in the world, with almost 800 million people at risk and more than 240 million people infected in 78 countries, causing high disease burden in many endemic areas, in particular in Sub-Saharan Africa [1-3]. There are five major schistosome species that infect humans: namely Schistosoma mansoni, S. haematobium, S. japonicum, S. intercalatum, and S. mekongi. The majority of human infections occur in Africa, caused by S. mansoni and S. haematobium, whereas S. japonicum and $S$. mekongi are confined to Asia. S. mansoni is also found in South and Central America [4-8]. Schistosomiasis is prevalent in tropical and subtropical regions, and transmission is associated with socio-environmental risk factors such as lack of access to safe water and appropriate sanitation, age- and occupation-related exposure, environmental changes (e.g., related to water development projects, land-use, and climate change), and human susceptibility to infection [3, 9-12].

The transmission of some human Schistosoma species, in particular for S. japonicum, S. mekongi, and S. mansoni, involves nonhuman mammalian hosts. The former two are widely recognized zoonoses that can infect a wide range of mammalian hosts [13, 14]. Natural infections of $S$. japonicum have been reported in more than 40 species of wild and domestic mammals, some of which have played important roles in maintaining the human schistosomiasis transmission cycle [14-17]. For example, studies in Poyang Lake, China, suggested that bovids, particularly water buffaloes (Bubalus bubalis), were key reservoirs of S. japonicum, contributing up to $75 \%$ of human infections in the region $[18,19]$, and similar findings were reported in the Philippines [20-22]. S. mansoni, which is primarily distributed across Africa, the Middle East, and parts of the Americas, has zoonotic potential due to its prevalence in nonhuman primates (NHPs), but there is a lack of conclusive information about its role as a zoonosis.

S. mansoni, the species of interest for this review, causes intestinal schistosomiasis. The principal intermediate hosts for S. mansoni are freshwater snails of the genus Biomphalaria. Infected snails shed cercariae, the larval, infectious form of the parasite, into the aquatic environment, where they then penetrate the skin of definitive hosts (e.g. humans) upon contact with contaminated water. Once inside the definitive hosts, the larvae develop into adults, which live in the blood vessels, where they mate and release eggs. These eggs can then be passed via the host's faeces into freshwater. These then hatch out, as miracidia, which in turn infect the snail hosts, completing the parasite transmission lifecycle. S. mansoni can infect both humans and NHPs, suggesting that when NHPs live in proximity to human communities, the two may share the endemic environment, creating opportunities for parasite spillover and local transmission maintenance.

Natural infections of $S$. mansoni in many species of NHPs have been reported, but the epidemiological role of NHPs in transmission, in particular their contribution to human infections, remains largely unknown. This is in part due to a dearth of information on interactions (e.g. exposure to the parasite and contamination of the environment) between humans and NHPs in the shared endemic environment, and an incomplete understanding of the transmission dynamics across the hosts. As the first step in establishing baseline information to inform and identify avenues for future research, we conducted a systematic review of $S$. mansoni infections in NHPs in Africa, to summarize information on NHP species implicated, Schistosoma infection status in African NHPs, their geographical distributions, and potential implications for human infection, based on the available evidence.

\section{Main text}

\section{Search strategy and selection criteria}

We conducted a comprehensive search for literature on $S$. mansoni infections among NHPs in Africa. This was done by searching databases including PubMed, Google Scholar, Web of Science, WHO library database, World Cat, and ScienceDirect, using the keywords "Schistosoma mansoni", "S. mansoni", "schistosomiasis", "schistosome", "zoonosis", "primate", "helminth", and "Africa". No time frame was specified in the search, but all of the studies identified occurred in the 1960s or later. The search was repeated in PubMed with no language constraint, but no additional results were returned. The reference lists of sources identified in this search were examined for additional relevant studies. Books, dissertations, conference abstracts, and unpublished reports were included.

Search results were initially screened based on title and abstract to determine eligibility. Those that mentioned $S$. mansoni and primates and took place in Africa were then further examined for relevant content. Each study needed to meet the following inclusion criteria: reporting $S$. mansoni infections in NHPs; occurring in Africa; and reporting natural infections rather than induced (e.g., laboratorybased infection).

\section{Data extraction and outcome measure}

Upon identification of eligible studies, relevant information from each study including survey location (e.g., site and country), year, primate species and genus, type of survey, diagnostic test, number of primates surveyed, and outcome measured (e.g., number of positive and negative tests) were 
extracted and entered into a standardized spreadsheet. Coordinates of the survey's location were identified from a Google search of the recorded study site. Type of survey described whether the primates were free-ranging or captive, and diagnostic procedure was based on parasitological tests (e.g., using faecal samples), serological tests (e.g., circulating antigen of the parasite), tissue examination, or necropsy. To explore whether there was an association between NHP and human infections, for each eligible study, we also searched for studies for corresponding human data based on a spatiotemporal 'match' of geographical area (e.g. at the scale of district or smaller) and survey year (e.g. \pm 5 years).

\section{Statistical analysis and mapping}

For all included studies, a qualitative summary of key study characteristics is provided. Data on the outcome measure (e.g., infection rate) were grouped by country and primate genus and were included in the meta-analysis using a random-effect model. In the analysis, various diagnostic tests were not differentiated. While heterogeneity statistics were estimated in the model for all studies (overall), studies within group, and between group comparison, $I^{2}$ (e.g., measuring the percentage of variations due to inter-study heterogeneity) and associated $P$-values [23] were reported for the former two for comparisons including four or more studies, and only $P$-value was reported for between group comparison. The distribution of studies, primate genera, and infection level were mapped for qualitative comparisons. Statistical analysis was performed in Stata (V11.1, StataCorp, College Station, Texas, USA) and mapping was conducted in ArcGIS (V10.2.2, ESRI, Redlands, California, USA).

\section{Results}

The search process and results are shown in Fig. 1. In total, 29 studies from 1960 to 2018 were included, and key characteristics of the studies summarized in Table 1. The studies encompassed ten countries, including Cameroon, Eritrea, Ethiopia, Gabon, Kenya, Nigeria, Senegal, Tanzania, Uganda, and Zimbabwe, exhibiting a wide geographical distribution across Africa (Fig. 2) and substantial variation in sample size (ranging from three to 206 by species) and infection rate (ranging from zero up to $90 \%$ ) among primate species across the regions (Table 1). A total of 22 species of NHPs, belonging to ten genera, were represented in the studies. There were 69 species-specific surveys, among which, 39 reported one or more infected primates. Among the 29 studies, 24 with sample size $>10$ were included in the meta-analysis. The 24 studies included primates from all ten countries, seven species (i.e. Cercocebus torquatus, Cercopithecus aethiops, Cercopithecus mitis, Pan troglodytes, Papio anubis, Papio cyanocephalus, and Papio hamadryas), belonging to three genera (i.e. Cercopithecus, Pan, and Papio). Overall, high heterogeneities in infection rate were observed across the NHP species/genera and survey sites/country (Table 1). Due to small sample numbers for some species and sites, our meta-analysis was performed at the scales of genus and country. The country with the highest rate of $S$. mansoni infections in NHPs was Eritrea, with an infection rate of $33 \%$ (95\% CI: 16-56\%) reported in one study that took place in 1970.

Overall, the analysis shows significant heterogeneity $\left(I^{2}=94.77 \%, P=0.00\right)$ across all studies, studies within country (Kenya $\left(I^{2}=95.14 \%, P=0.00\right)$, Tanzania $\left(I^{2}=\right.$ 85.94\%, $P=0.00)$, Ethiopia $\left(I^{2}=92.96 \%, P=0.00\right)$, and Senegal $\left.\left(I^{2}=92.19 \%, P=0.00\right)\right)$, no $I^{2}$ estimates for other

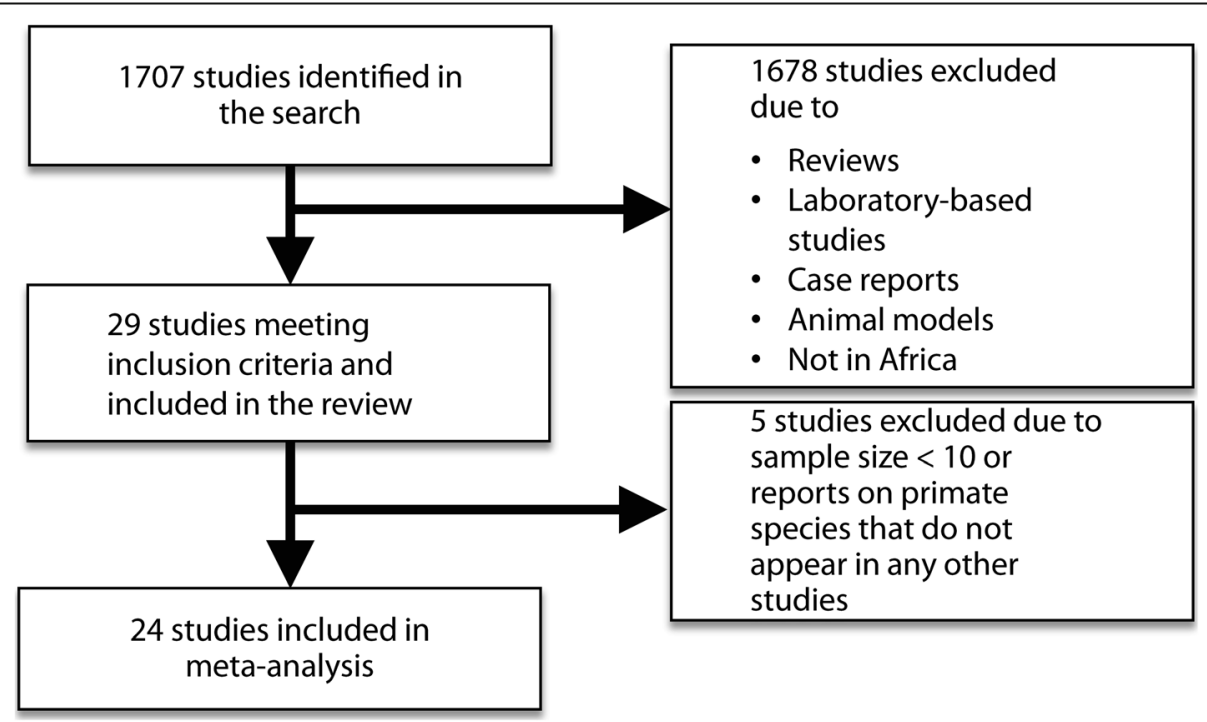

Fig. 1 Flowchart showing inclusion and exclusion of studies on Schistosoma mansoni infections of nonhuman primates in Africa and search results 
Table 1 Key characteristics of included studies on Schistosoma mansoni infections in nonhuman primates in Africa

\begin{tabular}{|c|c|c|c|c|c|c|}
\hline Year & Site & Host species & Study type & $\begin{array}{l}\text { Diagnostic } \\
\text { technique }\end{array}$ & $\begin{array}{l}\text { \% (infected/ } \\
\text { examined) }\end{array}$ & Reference \\
\hline 1960 & Kenya: Athi \& Kibwezi Rivers & Papio anubis & Wild & Necropsy & $23.88(32 / 134)$ & Miller [24] \\
\hline 1960 & Kenya:Machakos District and Lake Albert & Papio anubis & Wild & Necropsy & $54.69(35 / 64)$ & Nelson [25] \\
\hline 1961 & Kenya & Papio anubis & Wild & Necropsy & $28.00(42 / 150)$ & Strong et al. [26] \\
\hline 1969 & Tanzania: Lake Manyara National Park & Papio anubis & Wild & Necropsy & $80.00(4 / 5)$ & Fenwick [27] \\
\hline 1970 & Eritrea: Asmara & Cercopithecus aethiops & Wild & FECT & $33.33(6 / 18)$ & Cheever [28] \\
\hline 1970 & Tanzania: Lake Victoria & Cercopithecus aethiops & Wild & FECT & $23.40(11 / 47)$ & Cheever [28] \\
\hline 1972 & Tanzania & Papio spp. & Wild & Necropsy & $16.67(2 / 12)$ & Taylor et al. [29] \\
\hline 1974 & Zimbabwe & Papio ursinus & Wild & Necropsy & $1.96(1 / 51)$ & Goldsmid [30] \\
\hline 1979 & Ethiopia: Omo National Park & $\begin{array}{l}\text { Cercopithecus aethiops } \\
\text { Papio anubis }\end{array}$ & Wild & Necropsy & $\begin{array}{l}\text { CA: } 66.67(2 / 3) \\
\text { PA: } 50.00(3 / 6)\end{array}$ & Fuller et al. [31] \\
\hline 1982 & Kenya: Rift Valley, Lake Naivasha & Cercopithecus aethiops & Wild & Kato-Katz & $20.00(8 / 40)$ & Else et al. [32] \\
\hline 1989 & Senegal: Mt. Assirik & Papio papio & Wild & FECT & $23.01(9 / 39)$ & McGrew et al. [33] \\
\hline 1992 & Kenya: Kibwezi, Kivungoni Lake & Papio anubis & Wild & FECT & $24.43(32 / 131)$ & Muchemi [34] \\
\hline 1997 & Tanzania: Gombe National Park & Papio cynocephalus & Wild & FECT & $18.93(39 / 206)$ & $\begin{array}{l}\text { Muller-Graf et al. } \\
{[35]}\end{array}$ \\
\hline 1998 & Kenya: Nairobi & Papio cynocephalus & Wild & Kato-Katz & $4.35(4 / 92)$ & Munene et al. [36] \\
\hline 1998 & Kenya: Nairobi & $\begin{array}{l}\text { Papio cynocephalus } \\
\text { Cercopithecus aethiops }\end{array}$ & Wild & FECT & $\begin{array}{l}P C: 3.60(4 / 111) \\
\text { CA: } 4.88(6 / 123)\end{array}$ & Muriuki et al. [37] \\
\hline 1999 & Tanzania: Gombe National Park & Papio cynocephalus & Wild & ZSF & $2.86(1 / 35)$ & Murray et al. [38] \\
\hline 2001 & Ethiopia: Bishan Gari; Ethiopia: Burka Dita & Papio anubis & Wild & Kato-Katz & $\begin{array}{l}\text { BG: } 26.15(34 / 130) \\
\text { BD: } 12.09(11 / 91)\end{array}$ & Erko et al. [39] \\
\hline 2003 & Kenya: Mpala Wildlife Research Centre & Papio cynocephalus & Wild & FECT & $2.38(1 / 42)$ & Hahn et al. [40] \\
\hline 2004 & Ethiopia: Bishan Gari; Ethiopia: Burka Dita & Papio anubis & Wild & FECT & $\begin{array}{l}\text { BG: } 33.33(8 / 24) \\
\text { BD: } 11.43(4 / 35)\end{array}$ & Legesse et al. [41] \\
\hline 2006 & $\begin{array}{l}\text { Nigeria: Calabar, Afi Mountain Primate } \\
\text { Conservation Area }\end{array}$ & Papio anubis & Wild & FECT & $4.35(1 / 23)$ & Weyher et al. [42] \\
\hline 2011 & Senegal: Fongoli & Papio hamadryas & Wild & SNF \& FECT & $23.53(4 / 17)$ & Howells et al. [43] \\
\hline 2011 & $\begin{array}{l}\text { Nigeria: Calabar, Afi Mountain Primate } \\
\text { Conservation Area }\end{array}$ & Pan troglodytes & Semi-captive & MMT \& MBT & $35.71(10 / 28)$ & $\begin{array}{l}\text { Mbaya \& } \\
\text { Udendeye [44] }\end{array}$ \\
\hline 2011 & Cameroon: Yaounde & Erythrocebus patas & Captive & FECT & $33.33(1 / 3)$ & Pourrut et al. [45] \\
\hline 2011 & Uganda: Lake Victoria, Ngamba Island & Pan troglodytes & Wild & $\begin{array}{l}\text { ELISA, CCA, } \\
\text { Kato-Katz, qPCR }\end{array}$ & $89.74(35 / 39)$ & Standley et al. [46] \\
\hline 2012 & Tanzania: Gombe National Park & Papio anubis & Wild/ habituated & FECT & $11.90(15 / 126)$ & Bakuza [47] \\
\hline 2013 & Nigeria: Yankari National Park & Papio anubis & Wild & FECT & $4.30(2 / 46)$ & Mafuyai et al. [48] \\
\hline 2016 & Gabon: Loango National Park & $\begin{array}{l}\text { Gorilla gorilla } \\
\text { Pan troglodytes }\end{array}$ & Wild & MSF, MIF & $\begin{array}{l}\text { GG: } 62.50(5 / 8) \\
\text { PT: } 25.00(2 / 8)\end{array}$ & Cervena et al. [49] \\
\hline 2017 & Kenya: Tsavo West National Park & Papio anubis. & Semi- captive & FECT & $2.13(1 / 47)$ & Chimoyi [50] \\
\hline 2018 & Ethiopia: Oromia Regional State & $\begin{array}{l}\text { Cercopithecus aethiops } \\
\text { Papio anubis }\end{array}$ & Wild & Kato-Katz & $\begin{array}{l}\text { CA: } 21.60(8 / 37) \\
\text { PA: } 50.72(35 / 69)\end{array}$ & Kebede et al. [51] \\
\hline
\end{tabular}

Necropsy: Autopsy; FECT Formal-Ether Concentration Technique, Kato-Katz Kato-Katz thick smear, ZSF Zinc Sulfate Flotation, SNF Sodium Nitrate Flotation, ELISA Enzyme-Linked Immunosorbent Assay, CCA Circulating Cathodic Antigen Test, qPCR Real-time Polymerase Chain Reaction, MSF Modified Sheather's Flotation, MIF Merthiolate-lodine-Formalin Fecal Technique, MMT Modified McMaster Technique, MBT Modified Baerman's Techniquelf studies did not include a specific site, only the country is provided in this table

countries due to limited studies (Fig. 3), and significant heterogeneity between groups $(P=0.00)$. In Ethiopia, three studies (2001-2018) on Cercopithecus and Papio (Cercopithecus aethiops and Papio anubis) reported infection rates ranging from 0 to $52 \%$, with a pooled estimate of infection rate of $20 \%$ (95\% CI: 6-38\%). In
Nigeria, three studies (2006-2013) on Papio and Pan (Papio anubis and Pan troglodytes) reported infection rates ranging from 4 to $36 \%$, with a pooled estimate of infection of $12 \%$ (95\% CI: 0-35\%). In Kenya where nine studies (1960-2017) examined four species (Cercopithecus aethiops, Cercopithecus mitis, Papio anubis, and 


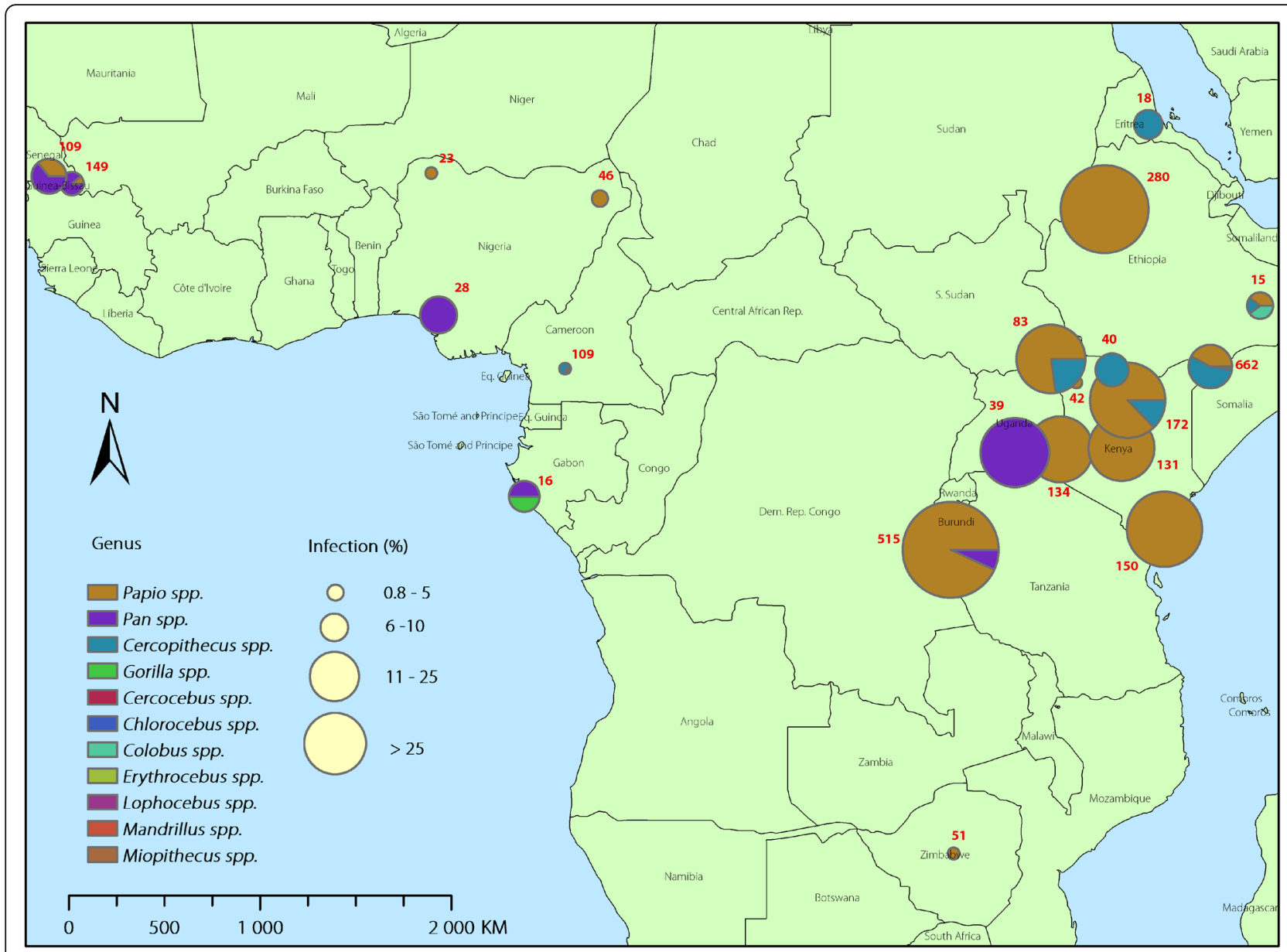

Fig. 2 Distribution of included studies and reported Schistosoma mansoni infections of nonhuman primates in Africa

Papio cyanocephalus), reported infection rates ranged between 0 and $55 \%$, with a pooled estimate of infection rate at $10 \%$ (95\% CI: 4-19\%). In Tanzania, six studies (1970-2012) on four species (Cercopithecus aethiops, Pan troglodytes, Papio anubis, and Papio cyanocephalus) reported infection rates between 0 and $23 \%$, and had a pooled estimate of $8 \%$ ( $95 \%$ CI: $2-17 \%$ ). In Uganda, the pooled estimate of infection rates was $8 \%$ (95\% CI: $4-$ 13\%) based on two studies on two species (Pan troglodytes and Papio cyanocephalus), and in Senegal, the pooled estimate of infection rates was 6\% (95\% CI: 0 23\%) based on two studies on three species (Pan troglodytes, Papio hamadryas, and Papio papio) (Fig. 3).

For analysis by genus, the finding shows significant heterogeneity in studies within NHP genus group (Papio $\left[I^{2}=93.92 \%, P=0.00\right]$, Cercopithecus $\left[I^{2}=89.52 \%, P\right.$ $=0.00]$, and $\left.\operatorname{Pan}\left[\mathrm{I}^{2}=98.05 \%, P=0.00\right]\right)$ but not between groups $(P=0.562)$ (Fig. 4). One species (Pan troglodytes) of primate in the genus Pan was reported in four studies spanning from 1989 to 2011 with a pooled estimate of infection rate of $15 \%$ (95\% CI: $0-55 \%)$. For the genus Papio, five species (Papio anubis, Papio cyanocephalus,
Papio hamadryas, Papio papio, and Papio ursinus) were reported in 21 studies from 1960 to 2018 with a pooled estimate of infection rate of $12 \%$ (95\% CI: 6-19\%). For the genus Cercopithecus, two species (Cercopithecus aethiops and Cercopithecus mitis) were reported in seven studies spanning from 1962 to 2018 with a pooled estimate of infection rate of $7 \%$ (95\% CI: 1-16\%) (Fig. 4). The majority of studies (27) examined wild NHPs while two examined captive NHPs $[36,46]$. Most studies diagnosed infection using fecal samples, and other methods included serological tests and necropsy (Table 1).

Nine studies were found to have a corresponding spatiotemporal 'match' of human schistosomiasis infection data based on site and survey year. Overall the association between human and nonhuman infections tended to be positive, although low sample size and high variation precluded statistical significance (Fig. 5, Pearson's $R=0.48, P=0.19$ ).

\section{Discussion}

Over the past several decades, extensive efforts to control schistosomiasis have transformed global patterns of 


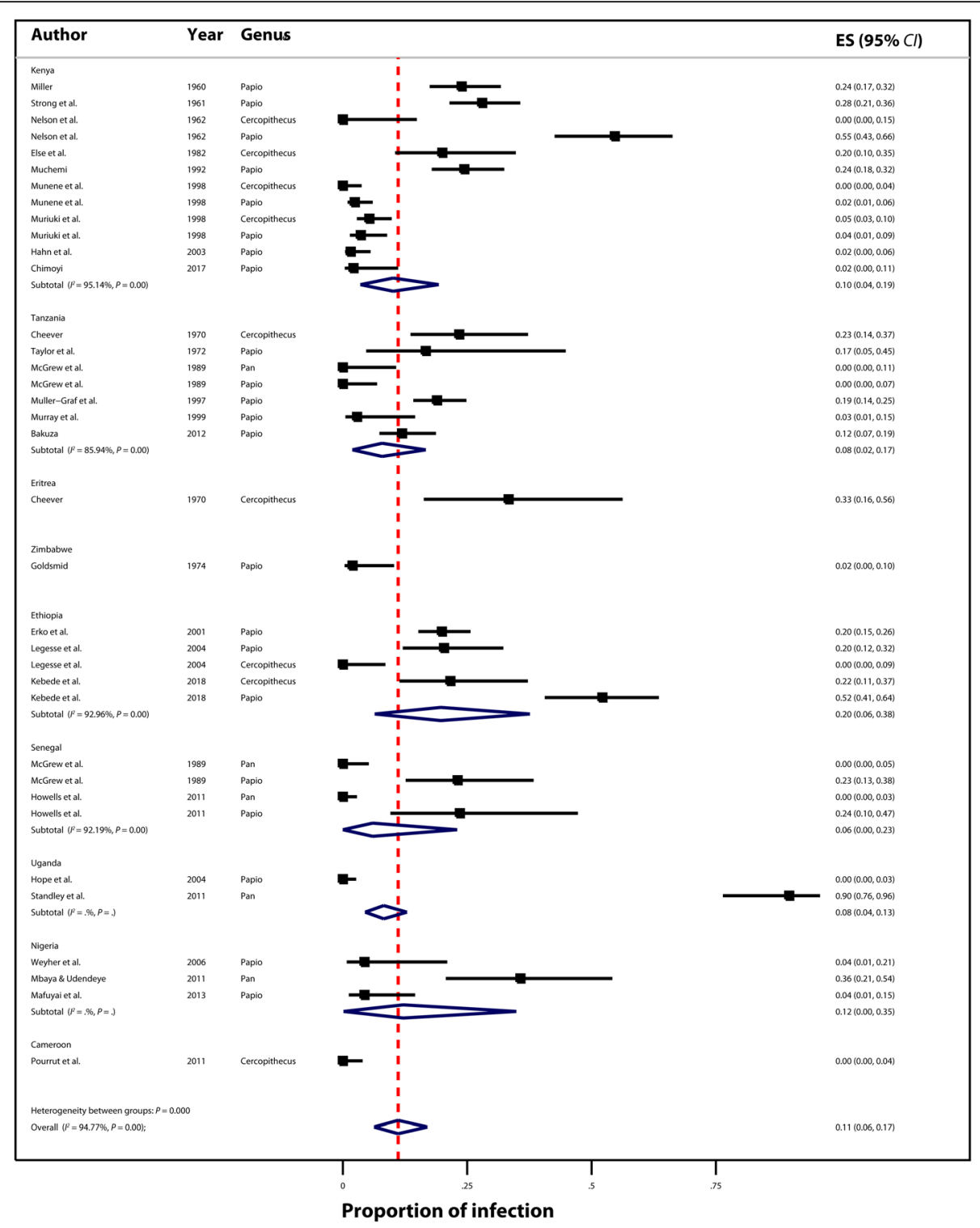

Fig. 3 Forest plot and pooled estimates of nonhuman primate Schistosoma mansoni infections by country (ES: Effect size)

the disease, motivating the development of an agenda to achieve global elimination of schistosomiasis as a public health problem in the years to come [3]. Among different control strategies in current use, controlling infection sources from nonhuman animal reservoirs has been one of key strategies underlying successful control in areas with identified zoonotic transmission of Schistosoma. This is well documented in China where mammalian hosts, particularly water buffalo, have been shown to play an important role in transmission and human infections of S. japonicum, and managing these animal reservoirs (e.g. via drug treatment and/or isolation) has been pivotal in disease control [52]. However, there are very limited studies on $S$. mansoni in potential animal reservoirs in comparison with human infection studies, despite reports of natural infections of the parasite in NHPs. This systematic review indicates that $S$. mansoni infections in African NHPs have been documented across a wide geographical area, and infection rates varied substantially across regions and species/genera (Fig. 2).

We found high heterogeneity in S. mansoni infections among African NPHs, and the underlying causes for this are not apparent. However, similarly to other infectious diseases reported in NHPs, the patterns of S. manosoni infection are likely mediated by factors associated with the primates themselves, such as group size, social status, habitat use, and behaviour [53, 54]. Kebede et al. reported that Papio baboons exhibited patterns of schistosomiasis infections that varied among populations and habitats in Ethiopia [51]. This suggests that within a species, habitat 
differences may affect infection rates at the subpopulation level. In Africa, NHPs are widely distributed, leading to overlaps with many human $S$. mansoni endemic areas (Fig. 6) and providing potential opportunities for exposure from humans and vice versa. Indeed, some early studies in Africa have pointed out that baboons are natural hosts for S. mansoni and can maintain transmission in the wild [55, 56]. Given the evidence for baboon-human overlaps and potential parasite sharing [57], a cycle of spillover and spillback maintenance of $S$. mansoni is plausible. Several studies included in this review reported lifecycle experiments of $S$. mansoni from vervet monkeys in which eggs shed by the animals hatched into viable miracidia that infected snails. The infected snails then shed cercariae to infect laboratory mice for subsequent worm harvest, confirming the capacity of the NHPs to maintain local transmission $[39,41]$.

In this review, the association between NHP and human infections by $S$. mansoni based on available data was also explored. Despite substantial variation and a low sample size, the overall trend was positive. However, such association should be interpreted with a caveat. The information for human and NHP surveys were based on different sampling and diagnostic methods, and certain species of primates might be over-represented (e.g., those most likely to be hunted). However, it is apparent that the overlap of NHP habitats and S. mansoni endemic areas has high potential for zoonotic transmission (Fig. 6). Although the epidemiological roles of NHPs in schistosomiasis transmission to humans remain largely unknown, their close interactions in many endemic areas (e.g., sharing water environments that sustain the disease transmission) have raised concerns that the NHPs' roles in the disease transmission may not be negligible.

To confront the challenge of better understanding this NHP role in the $S$. mansoni transmission, there are knowledge gaps to overcome. Improved understanding of the molecular characteristics of Schistosoma strains circulating in humans and NHPs are needed. A few

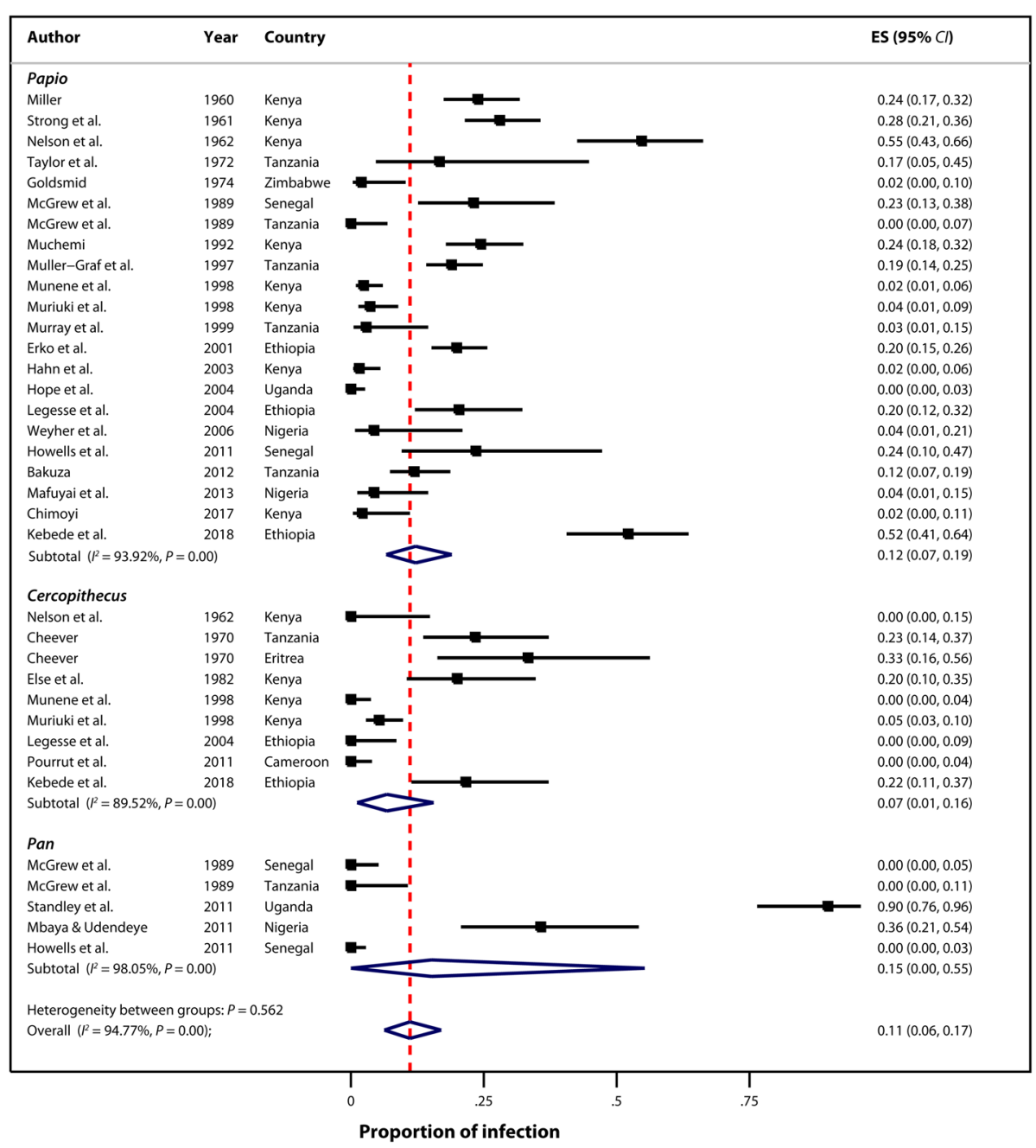

Fig. 4 Forest plot and pooled estimates of nonhuman primate Schistosoma mansoni infections by genus (ES: Effect size) 


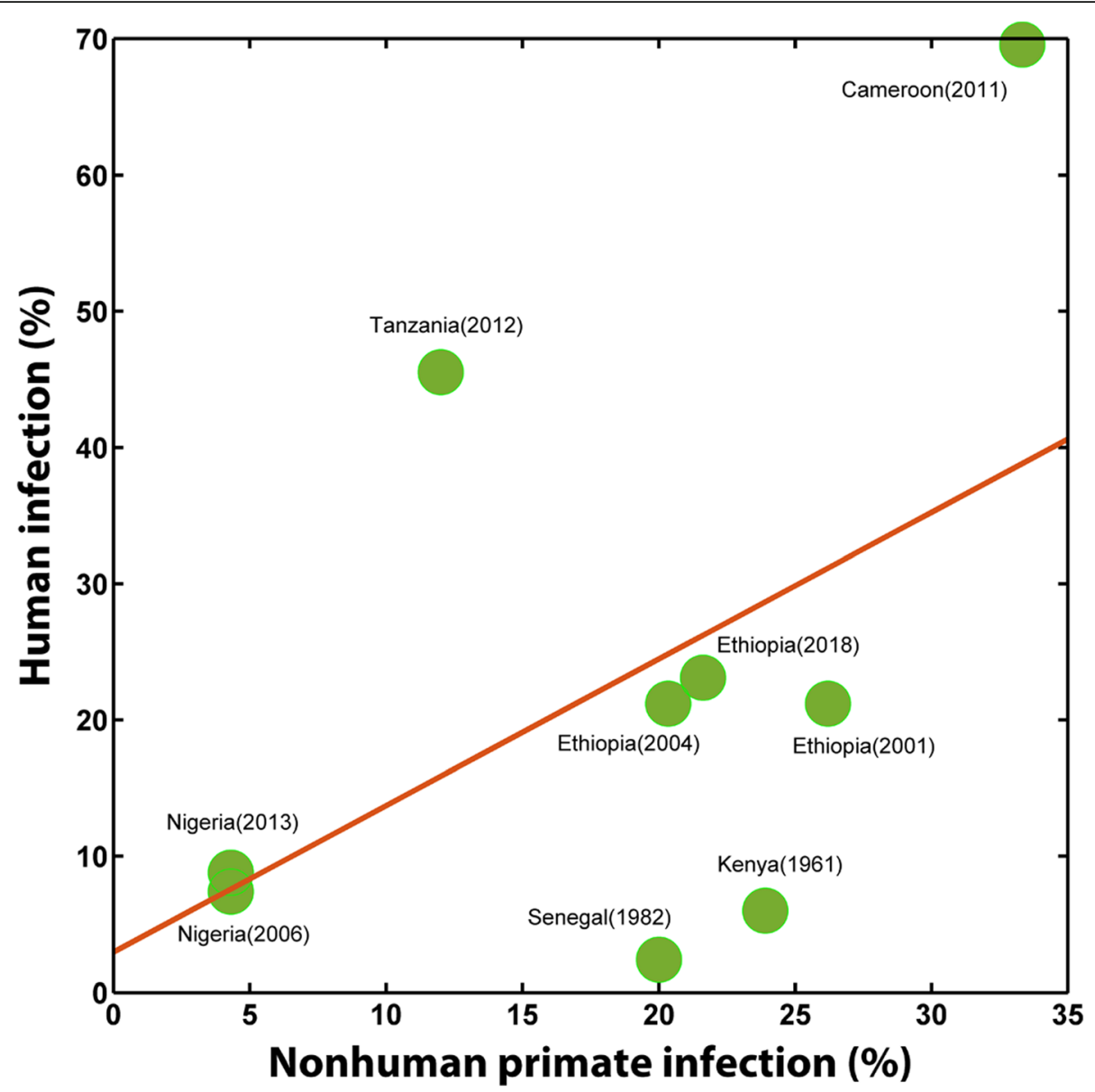

Fig. 5 Association between nonhuman primate and human infections by Schistosoma mansoni

studies described in this review made initial explorations of molecular characterization of the parasites. Bakuza et al. performed a molecular analysis of schistosome eggs from baboons and reported that S. mansoni existed in both humans and baboons, but the gene region sequenced was not variable enough to assess whether they shared the same strain [47]. Another study used isoenzyme electrophoresis to compare human and baboon $S$. mansoni strains and found no unique alleles or indication of distinctions between the parasite populations [34]. However, this was not conclusive and more sensitive techniques are needed to confirm the similarity of the parasites from the two types of hosts [34].

Still less well understood are the interactions between the NHPs and humans that could promote zoonotic schistosomiasis transmission. For example, do the humans and NHPs share exposure environments (e.g., water contact and contamination sites)? If so, what are spatial and temporal windows of overlaps? Several studies mentioned crop-raiding as one of interactions with human populations that may influence disease transmission [42, 43].
Another paper mentioned the overlap of ecotourism and NHP habitat at the shores of Lake Langano in Ethiopia and the surrounding forest reserve, which could have implications for transmission through a shared water source [39]. Rigorous quantification of the spatiotemporal overlaps and shared resource use behaviour would greatly improve our understanding of this transmission system.

Nonhuman primate infections by $S$. mansoni not only have potential human public health importance but also notable conservation implications when considering spillover and spillback scenarios. For instance, Cervena et al. [49] surveyed 8 free-ranging Western lowland gorillas (Gorilla gorilla gorilla) and found that 5 of them were infected by $S$. mansoni. Gorillas are classified by the International Union for Conservation of Nature (IUCN) as critically endangered [58], and are highly susceptible to spillover infections from humans [59]. Do S. mansoni infections pose health threats to the gorillas? If so, what are the associated morbidities? Other primate species identified in this review are also of conservation concern: Pan troglodytes is endangered and Papio papio is classified as 


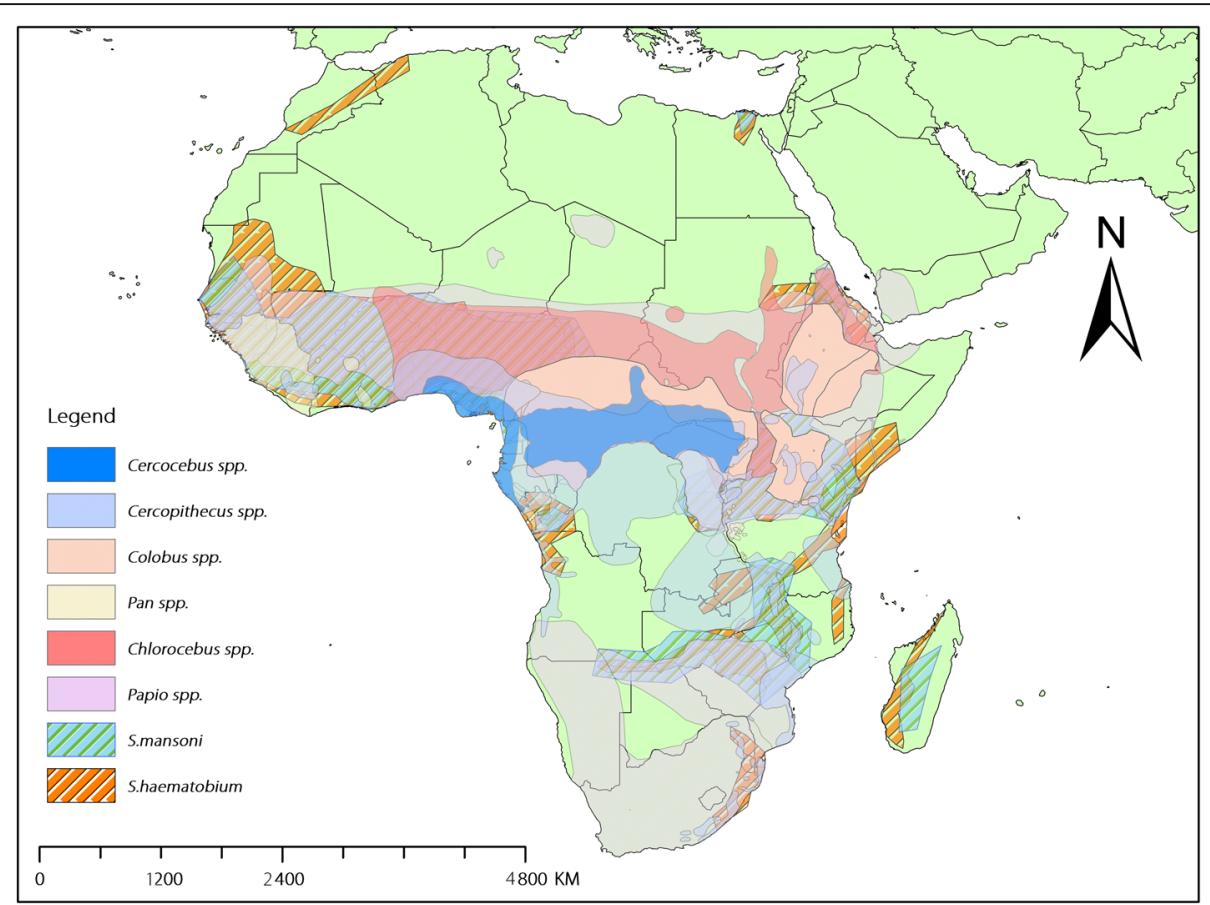

Fig. 6 Distribution of endemic areas of Schistosoma mansoni and S. haematobium, and major genera of nonhuman primates found to be naturally infected by S. mansoni in Africa (Data sources: nonhuman primate - https://www.iucnredlist.org; schistosomiasis

- http://www.thiswormyworld.org)

near-threatened [60, 61]. Further knowledge on S. mansoni infections of NHPs and its health impacts, if any, may provide important information for the management and preservation of wildlife populations. This would also clarify roles of NHP species as definitive, maintenance (impacted or not), or spillover hosts.

Our meta-analysis was limited to studies with directly comparable information. Primate genera which only appeared in single studies were excluded from the meta-analysis part of this review. The study had several additional limitations. First, although studies with sample size $<10$ were excluded from the meta-analysis, some included studies still had modest sample sizes and therefore may not adequately represent population level infection rates. Sample sizes in the studies varied considerably, from 3 to 206, with different sampling strategies, so pooled estimates were likely subject to impacts of varying sampling schemes. Second, the studies used 12 different diagnostic techniques for infection with FECT, Kato-Katz thick smear, and necropsy being the most commonly used. These tests have different levels sensitivity and specificity in the diagnosis of schistosome presence, which we did not take into account explicitly, and which may introduce bias in the calculation of pooled estimates. Nevertheless, such estimates represent a conservative quantification of actual infections, and to some extent, serve the purpose of this review.

\section{Conclusions}

There is substantial overlap of habitats of nonhuman primate (NHP) species and schistosomiasis endemic areas in Africa. Our review suggests that the reported $S$. mansoni infection rates in NHPs are generally high, with substantial variations across geographical regions and primate species/genera. There is a pressing need for an improved understanding about the potential zoonotic roles of these NHPs in the transmission cycle of human schistosomiasis.

\section{Additional file}

Additional file 1: Multilingual abstracts in the five official working languages of the United Nations. (PDF $504 \mathrm{~kb}$ )

\section{Abbreviations \\ CCA: Circulating cathodic antigen test; Cl: Confidence interval; ELISA: Enzyme-linked immunosorbent assay; FECT: Formal-ether concentration technique; IUCN: International Union for Conservation of Nature; MBT: Modified Baerman's technique; MIF: Merthiolate-iodine-formalin fecal technique; MMT: Modified McMaster technique; MSF: Modified Sheather's flotation; NHP: Non-human primate; NTD: Neglected tropical disease; GPCR: Real-time polymerase chain reaction; SNF: Sodium nitrate flotation; WHO: World Health Organization; ZSF: Zinc sulfate flotation}

\section{Acknowledgements}

We would like to thank Dr. Abraham Mengist Legesse who helped to review our analysis. 


\section{Funding}

SL is supported in part by the National Institutes of Health (grant R01Al125842) and a grant from the World Health Organization. Publication of this article was funded in part by the University of Florida Open Access Publishing Fund.

\section{Availability of data and materials}

The datasets analysed during the current study will be available in the following repositories (Open Science Framework [https://osf.io/]) or upon request to the authors.

\section{Authors' contribution}

$S L$ and LR conceived the study. LR performed the data search and compilation. $L R$ and SL performed the analysis. SR helped taxonomy of primates involved in the studies. BE helped on data compilation. KP helped on the development of maps. LR and SL contributed the first draft. Everyone contributed to revising the manuscript. All authors read and approved the final manuscript.

\section{Ethics approval and consent to participate}

Not applicable.

\section{Consent for publication}

Not applicable.

\section{Competing interests}

The authors declare that they have no competing interests.

\section{Author details}

'Department of Microbiology \& Cell Science, University of Florida, Gainesville, FL 32610, USA. ${ }^{2}$ Aklilu Lemma Institute of Pathobiology, Addis Ababa University, Addis Ababa, Ethiopia. ${ }^{3}$ Department of Environmental and Global Health, College of Public Health and Health Professions, University of Florida, Gainesville, FL 32610, USA. "Department of Geography, University of Florida, Gainesville, FL 326102, USA. ${ }^{5}$ Emerging Pathogens Institute, University of Florida, Gainesville, FL 32610, USA.

\section{Received: 3 December 2018 Accepted: 17 April 2019}

\section{Published online: 10 May 2019}

\section{References}

1. Engels D, Chitsulo L, Montresor A, Savioli L. The global epidemiological situation of schistosomiasis and new approaches to control and research. Acta Trop. 2002;82(2):139-46

2. Steinmann P, Keiser J, Bos R, Tanner M, Utzinger J. Schistosomiasis and water resources development: systematic review, meta-analysis, and estimates of people at risk. Lancet Infect Dis. 2006;6(7):411-25.

3. World Health Organization. Elimination of schistosomiasis. In: SIXTY-FIFTH WORLD HEALTH ASSEMBLY. Geneva: World Health Organization; 2012. WHA65/2012/REC/1:PP.36-37ttps://www.who.int/neglected_diseases/ mediacentre/WHA 65.21_Eng.pdf. Accessed 10 Sept 2018.

4. Barbosa VS, RJ EG, Loyo RM, Barbosa CS. Modelling of the distribution of Biomphalaria glabrata and Biomphalaria straminea in the metropolitan region of Recife, Pernambuco, Brazil. Geospat Health. 2016;11(3):490.

5. Barboza DM, Zhang C, Santos NC, Silva MM, Rollemberg CV, de Amorim FJ, et al. Biomphalaria species distribution and its effect on human Schistosoma mansoni infection in an irrigated area used for rice cultivation in Northeast Brazil. Geospat Health. 2012;6(3):S103-9.

6. Caldeira RL, Teodoro TM, Jannotti-Passos LK, Lira-Moreira PM, Goveia CO Carvalho OD. Characterization of south American snails of the genus Biomphalaria (Basommatophora: Planorbidae) and Schistosoma mansoni (Platyhelminthes: Trematoda) in Molluscs by PCR-RFLP. Biomed Res Int. 2016;2016:1045391.

7. Sturrock RF. Distribution of the snail Biomphalaria glabrata, intermediate host of Schistosoma mansoni, within a St Lucian field habitat. Bull World Health Organ. 1975;52(3):267-72.

8. Zoni AC, Catala L, Ault SK. Schistosomiasis prevalence and intensity of infection in Latin America and the Caribbean countries, 1942-2014: a systematic review in the context of a regional elimination goal. PLoS Negl Trop Dis. 2016;10(3):e0004493.

9. Gryseels B, Polman K, Clerinx J, Kestens L. Human schistosomiasis. Lancet. 2006;368(9541):1106-18.
10. Liang S, Seto EY, Remais JV, Zhong B, Yang C, Hubbard A, et al. Environmental effects on parasitic disease transmission exemplified by schistosomiasis in western China. Proc Natl Acad Sci U S A. 2007;104(17):7110-5.

11. Remais J, Liang S, Spear RC. Coupling hydrologic and infectious disease models to explain regional differences in schistosomiasis transmission in southwestern China. Environ Sci Technol. 2008:42(7):2643-9.

12. Spear RC, Seto E, Liang S, Birkner M, Hubbard A, Qiu DC, et al. Factors influencing the transmission of Schistosoma japonicum in the mountains of Sichuan Province of China. Am J Trop Med Hyg. 2004;70(1):48-56.

13. Ohmae H, Sinuon M, Kirinoki M, Matsumoto J, Chigusa Y, Socheat D, et al. Schistosomiasis mekongi: from discovery to control. Parasitol Int. 2004:53(2):135-42.

14. Zhou YB, Liang S, Jiang QW. Factors impacting on progress towards elimination of transmission of schistosomiasis japonica in China. Parasit Vectors. 2012;5:275.

15. Gray DJ, Williams GM, Li Y, McManus DP. Transmission dynamics of Schistosoma japonicum in the lakes and marshlands of China. PLoS One. 2008:3(12):e4058.

16. Guo JG, Ross AG, Lin DD, Williams GM, Chen HG, Li Y, et al. A baseline study on the importance of bovines for human Schistosoma japonicum infection around Poyang Lake, China. Am J Trop Med Hyg. 2001;65(4):272-8.

17. Wang QZ, Wang TP, Zhang SQ. Research progress on transmission capacity of reservoir host of Schistosoma japonicum. Zhongguo Xue Xi Chong Bing Fang Zhi Za Zhi. 2013:25(1):86-9 (in Chinese)

18. Gray DJ, Williams GM, Li YS, Chen HG, Forsyth S, Li R, et al. The role of bovines in human Schistosoma japonicum infection in the Peoples' republic of China. Am J Trop Med Hyg. 2009;81(5):301.

19. Guo J, Li Y, Gray D, Ning A, Hu G, Chen H, et al. A drug-based intervention study on the importance of buffaloes for human Schistosoma japonicum infection around Poyang Lake, People's Republic of China. Am J Trop Med Hyg. 2006;74(2):335-41.

20. Gordon CA, Acosta LP, Gobert GN, Jiz M, Olveda RM, Ross AG, et al. High prevalence of Schistosoma japonicum and Fasciola gigantica in bovines from Northern Samar, the Philippines. PLoS Negl Trop Dis. 2015;9(2):e0003108.

21. Gordon CA, Acosta LP, Gray DJ, Olveda RM, Jarilla B, Gobert GN, et al. High prevalence of Schistosoma japonicum infection in Carabao from Samar Province, the Philippines: implications for transmission and control. PLoS Negl Trop Dis. 2012:6(9):e1778.

22. Wu HW, Qin YF, Chu K, Meng R, Liu Y, McGarvey ST, et al. High prevalence of Schistosoma japonicum infection in water buffaloes in the Philippines assessed by real-time polymerase chain reaction. Am J Trop Med Hyg. 2010; 82(4):646-52.

23. Higgins JP, Thompson SG, Deeks JJ, Altman DG. Measuring inconsistency in meta-analyses. BMJ. 2003;327(7414):557-60.

24. Miller JH. Papio doguera (dog face baboon), a primate reservoir host of Schistosoma mansoni in East Africa. Royal Soc Trop Med Hyg. 1960;54(1):44-6.

25. Nelson GS. Schistosome infections as zoonoses in Africa. Royal Soc Trop Med Hyg. 1960;54(4):301-16.

26. Strong JP, McGill HC, Miller JH. Schistosomiasis mansoni in the Kenya baboon. Am J Trop Med Hyg. 1961;10(1):25-32.

27. Fenwick A. Baboons as reservoir hosts of Schistosoma mansoni. Royal Soc Trop Med Hyg. 1969:63(5):557-67.

28. Cheever AW, Kirschstein RL, Reardon LV. Schistosoma mansoni infection of presumed natural origin in Cercopithecus monkeys from Tanzania and Ethiopia. Bull World Health Org. 1970;42(3):486.

29. Taylor MG, Nelson GS, Andrews BJ. A case of natural infection of S. haematobium in a Senegalese baboon (Papio sp,). Royal Soc Trop Med Hyg 1972;66(1):16-17. doi:0.1016/0035-9203(72)90028-4.

30. Goldsmid JM. The intestinal helminthzoonoses of primates in Rhodesia. Ann Soc Belg Med Trop. 1974:54(2):87-101.

31. Fuller GK, Lemma A, Haile T. Schistosomiasis in Omo National Park of Southwest Ethiopia. Am J Trop Med Hyg. 1979;28(3):526-30.

32. Else JG, Satzger M, Sturrock RF. Natural infections of Schistosoma mansoni and S. haematobium in Cercopithecus monkeys in Kenya. Annals Trop Med Parasitol. 1982;76(1):111-2.

33. McGrew WC, Tutin CEG, Collins DA, File SK. Intestinal parasites of sympatric Pan troglodytes and Papio spp. at two sites: Gombe (Tanzania) and Mt. Assirik (Senegal). Am J Primatol. 1989:17(2):147-55.

34. Muchemi GKM. Baboons as maintenance hosts of human schistosomiasis in Kenya (Doctoral Dissertation, University of Liverpool). (1992) https://profiles. uonbi.ac.ke/gmuchemi/publications/muchemi-gkm-1992-baboons- 
maintenance-hosts-human-schistosomiasis-kenya-ph-d-th . Accessed 10 Sept 2018.

35. Muller-Graf CD, Collins DA, Packer C, Woolhouse ME. Schistosoma mansoni infection in a natural population of olive baboons (Papio cynocephalus anubis) in Gombe stream National Park, Tanzania. Parasitol. 1997;115(6):621-7.

36. Munene E, Otsyula M, Mbaabu DAN, Mutahi WT, Muriuki SMK, Muchemi GM. Helminth and protozoan gastrointestinal tract parasites in captive and wild-trapped African non-human primates. Vet Parasitol. 1998;78(3):195-201.

37. Muriuki SMK, Murugu RK, Munene E, Karere GM, Chai DC. Some gastrointestinal parasites of zoonotic (public health) importance commonly observed in old world non-human primates in Kenya. Acta Trop. 1998;71 (1):73-82.

38. Murray S, Stem C, Boudreau B, Goodall J. Intestinal parasites of baboons (Papio cynocephalus anubis) and chimpanzees (Pan troglodytes) in Gombe National Park. J Zoo Wildlife Med. 2000;31(2):176-8.

39. Erko B, Gebre-Michael T, Balcha F, Gundersen SG. Implication of Papio anubis in the transmission of intestinal schistosomiasis in three new foci in Kime area, Ethiopia. Parasitol Int. 2001;50(4):259-66.

40. Hahn NE, Proulx D, Muruthi PM, Alberts S, Altmann J. Gastrointestinal parasites in free-ranging Kenyan baboons (Papio cynocephalus and $P$. anubis). Int J Primatol. 2003;24(2):271-9.

41. Legesse M, Erko B. Zoonotic intestinal parasites in Papio anubis (baboon) and Cercopithecus aethiops (vervet) from four localities in Ethiopia. Acta Trop. 2004;90(3):231-6.

42. Weyher AH, Ross C, Semple S. Gastrointestinal parasites in crop raiding and wild foraging Papio anubis in Nigeria. Int J Primatol. 2006;27(6):15-9.

43. Howells ME, Pruetz J, Gillespie TR. Patterns of gastro-intestinal parasites and commensals as an index of population and ecosystem health: the case of sympatric Western chimpanzees (Pan troglodytes verus) and Guinea baboons (Papio hamadryas papio) at Fongoli, Senegal. Am J Primatol. 2011;73(2):173-9.

44. Mbaya AW, Udendeye UJ. Gastrointestinal parasites of captive and freeroaming Primates at the Afi mountain Primate Conservation area in Calabar, Nigeria and their zoonotic implications. Pakistan J Bio Sci. 2011;14(13):709-14.

45. Pourrut $X$, Diffo JL, Somo RM, Bilong Bilong CB, Delaporte E, LeBreton M, et al. Prevalence of gastrointestinal parasites in primate bushmeat and pets in Cameroon. Vet Parasitol. 2010;175(1-2):187-91.

46. Standley CJ, Mugisha L, Verweij JJ, Adriko M, Arinaitwe M, Rowell C, et al. Confirmed infection with intestinal schistosomiasis in semi-captive wildborn chimpanzees on Ngamba Island, Uganda. Vector Borne Zoonotic Dis. 2011;11(2):169-76.

47. Bakuza JS. Epidemiology of Schistosoma mansoni infection in sympatric humans and non-human primates in the Gombe ecosystem Tanzania. (2012) http://theses.gla.ac.uk/3652. Accessed 10 Sept 2018.

48. Mafuyai HB, Barshep Y, Audu BS, Kumbak D, Ojobe TO. Baboons as potential reservoirs of zoonotic gastrointestinal parasite infections at Yankari National Park, Nigeria. Afr Health Sci. 2013;13(2):252-4.

49. Červená B, Brant SV, Fairet E, Shirley MH, Petrželková KJ, Modrý D. Schistosoma mansoni in Gabon: emerging or ignored? Am J Trop Med Hyg. 2016;95(4):849-51.

50. Chimoyi MF. Zoonotic gastrointestinal helminths and hemoparasites of baboons in Tana River, Tsavo and Laikipia. Kenya: Kenyatta University; 2012. https://ir-library.ku.ac.ke/handle/123456789/18134. Accessed 10 Sept 2018

51. Kebede T, Negash Y, Erko B. Schistosoma mansoni infection in human and nonhuman primates in selected areas of Oromia regional state, Ethiopia. J Vector Borne Dis. 2018;55(2):116-21.

52. Wang $L D$, Chen $H G$, Guo JG, Zeng XJ, Hong XL, Xiong JJ, et al. A strategy to control transmission of Schistosoma japonicum in China. N Engl J Med. 2009;360(2):121-8.

53. Cormier LA, Jolly PE. The primate zoonoses: culture change and emerging diseases. New York: Routledge; 2018.

54. Ryan SJ, Jones JH, Dobson AP. Interactions between social structure, demography, and transmission determine disease persistence in Primates. PLoS One. 2013;8(10):e76863.

55. Farah IO, Nyindo M, Suleman MA, Nyaundi J, Kariuki TM, Blanton RE, et al. Schistosoma mansoni: development and modulation of the granuloma after or multiple exposures in the baboon (Papio cynocephalus anubis). Exp Parasitol. 1997;86(2):93-101.

56. Nyindo M, Farah IO. The baboon as a non-human primate model of human schistosome infection. Parasitol Today. 1999;15(12):478-82.

57. Ryan SJ, Brashares JS, Walsh C, Milbers K, Kilroy C, Chapman CA. A survey of gastrointestinal parasites of olive baboons (Papio anubis) in human settlement areas of mole National Park, Ghana. J Parasitol. 2012;98(4):885-8.
58. Maisels F, Bergl RA, Williamson EA. Gorilla gorilla. The IUCN red list of threatened species (2016). Accessed 10 Sept 2018

59. Ryan SJ, Walsh PD. Consequences of non-intervention for infectious disease in African great apes. PLoS One. 2011:6(12):e29030.

60. Humle T, Maisels F, Oates JF, Plumptre A, Williamson EA. Pan troglodytes. The IUCN Red List of Threatened Species (2016). Accessed 10 Sept 2018.

61. Oates JF, Gippoliti S, Groves CP. Papio papio. The IUCN Red List of Threatened Species (2008). Accessed 10 Sept 2018

\section{Ready to submit your research? Choose BMC and benefit from:}

- fast, convenient online submission

- thorough peer review by experienced researchers in your field

- rapid publication on acceptance

- support for research data, including large and complex data types

- gold Open Access which fosters wider collaboration and increased citations

- maximum visibility for your research: over $100 \mathrm{M}$ website views per year

At $\mathrm{BMC}$, research is always in progress.

Learn more biomedcentral.com/submissions 